\title{
Unexpected Products and Reaction Mechanisms of the Aqueous Chlorination of Cimetidine
}

\author{
Jeffrey M. Buth ${ }^{\ddagger}$, William A. Arnold ${ }^{\S^{*}}$, and Kristopher McNeill \\ $\ddagger$ \\ Department of Chemistry, University of Minnesota, 207 Pleasant Street SE, Minneapolis, \\ MN 55455 \\ Department of Civil Engineering, University of Minnesota, 500 Pillsbury Dr. SE, \\ Minneapolis, MN 55455 \\ *Corresponding author (W.A.A.) phone: 612-625-8582; fax: 612-626-7750; \\ e-mail: arno1032@umn.edu \\ *Corresponding author (K.M.) phone: 612-625-0781; fax: 612-626-7541; \\ e-mail: moneill@chem.umn.edu
}

Contents

Text S1. Collection, preparation, and analysis of wastewater. 2

Text S2. Ammonium chloride quenching control experiments. 3

Figure S1. Stability of cimetidine and products towards chloramines. 4

Figure S2. Degradation of cimetidine by free chlorine in wastewater. 5

Figure S3. HPLC $t_{\mathrm{R}}$ match of 2 with cimetidine sulfoxide. 6

Figure S4. H-NMR spectrum of 2 . 6

Figure S5. HPLC t match of 1 with 4-hydroxymethyl-5- 7 methyl-1H-imidazole

Figure S6. H-NMR spectrum of $\mathbf{1}$.

Figure S7. ESI mass spectrum of 3 and $4 . \quad 8$

Figure S8. HMBC NMR spectra of $\mathbf{1}$ and $\mathbf{3}$. 9

Figure S9. ESI ${ }^{+}$and CI mass spectra of 4-d .

Figure S10. 'H-NMR spectrum of 4 and 4-d . 10

Figure S11. FTIR spectrum of $4 . \quad 11$

Figure S12. Degradation of $\mathbf{3}$ and $\mathbf{4}$ by free chlorine. 11 
Text S1. Collection, Preparation, and Analysis of Wastewater

\section{Sample Procurement}

Wastewater effluent was obtained from a Twin Cities municipal wastewater treatment plant on November 9,2006. A grab sample was collected at the point after secondary activated sludge treatment where chlorine disinfectant is typically applied, though the plant was not disinfecting at the time of year when the samples were obtained. The wastewater was filtered through Millipore $0.20 \mu \mathrm{m}$ filters, adjusted to $\mathrm{pH} 2$ with concentrated sulfuric acid for preservation, and stored at $4{ }^{\circ} \mathrm{C}$ until the experiments were performed. For wastewater experiments at $\mathrm{pH} 4,7$, and 10 , the wastewater $\mathrm{pH}$ was adjusted with sulfuric acid and sodium hydroxide.

\section{DOC Analysis}

Wastewater samples were analyzed on a Shimadzu TOC 5000A analyzer for dissolved organic carbon (DOC) following the procedures of Aiken et al. (1). DOC was detected as non-purgeable organic carbon (NPOC) following acidification of the samples to $\mathrm{pH} 2.0$ with concentrated sulfuric acid. Potassium hydrogen phthalate (KHP) was used to generate standard curves for the analysis. Samples were analyzed in triplicate and had a DOC value of $8.5 \pm 0.9 \mathrm{mg} \mathrm{C} \mathrm{L}^{-1}$.

\section{$\underline{\text { Ammonia Analysis }}$}

Ammonia was measured colorimetrically by the Nessler method (2) using a Beckman DU 530 Life Science UV/Vis Spectrophotometer, analyzing at $420 \mathrm{~nm}$. Nessler's Reagent was purchased from Hach Company. Samples were analyzed in triplicate and a result of $0.2 \mathrm{mg} \mathrm{NH}_{4}^{+}-\mathrm{N} \mathrm{L}^{-1}$ was obtained. 
Text S2. Ammonium Chloride Quenching Control Experiments.

The use of ammonium chloride $\left(\mathrm{NH}_{4} \mathrm{Cl}\right)$ as an agent to quench free chlorine reactions has been demonstrated in the literature (3). $\mathrm{NH}_{4} \mathrm{Cl}$ reacts rapidly with free chlorine, forming chloramines. Though chloramines are active oxidants, they generally react with organic substrates several orders of magnitude slower than free chlorine, effectively quenching a reaction over a suitable time window for analysis. Control experiments were performed to verify that the chlorination reactions in this work were effectively quenched by $\mathrm{NH}_{4} \mathrm{Cl}$ by testing the stability of cimetidine and its chlorination products in $\mathrm{NH}_{4} \mathrm{Cl}$-quenched free chlorine solutions.

To test the stability of cimetidine and cimetidine sulfoxide in the presence of $\mathrm{NH}_{4} \mathrm{Cl}$ quenched free chlorine, solutions of $0.74 \mathrm{mM} \mathrm{NaOCl}$ in $\mathrm{pH} 4$ acetate, $\mathrm{pH} 7$ phosphate, and $\mathrm{pH} 10$ carbonate were prepared. Each was quenched with a 2.5-fold molar excess of $\mathrm{NH}_{4} \mathrm{Cl}$ relative to the initial $\mathrm{NaOCl}$ concentration. After the addition of $\mathrm{NH}_{4} \mathrm{Cl}$, an aliquot of cimetidine or cimetidine sulfoxide was added to achieve a $\left[\mathrm{NaOCl}_{0}\right]$ :[substrate] ratio of $10: 1$, where $\left[\mathrm{NaOCl}_{0}\right]$ is the concentration of $\mathrm{NaOCl}$ prior to the addition of $\mathrm{NH}_{4} \mathrm{Cl}$. The reaction mixture was analyzed repeatedly by HPLC to monitor the stability of cimetidine or cimetidine sulfoxide in the presence of quenched free chlorine. Figure S1 shows plots of the cimetidine or cimetidine sulfoxide concentration at each time point normalized to the initial concentration vs. time at $\mathrm{pH} 4,7$, and 10 . These results show that cimetidine is very reactive with the chloramines formed in the free chlorine quenching reactions, degrading by at least $83 \%$ within $3 \mathrm{~min}$ at each $\mathrm{pH}$ studied. However, because cimetidine reacts faster with free chlorine than chloramines, degrading completely by the first time point at $10 \mathrm{~s}$ in the free chlorine reactions presented in this work, it is not important that it is unstable after quenching. Cimetidine sulfoxide was found to be very stable in the presence of chloramines at $\mathrm{pH} 7$ and 10, while it degraded slowly (20\% in $2.5 \mathrm{hr}$ ) at $\mathrm{pH} 4$.

To monitor the stability of the other cimetidine chlorination products in the presence of quenched free chlorine, $97 \mu \mathrm{M}$ cimetidine solutions in $\mathrm{pH} 4$ acetate, $\mathrm{pH} 7$ phosphate, or $\mathrm{pH} 10$ carbonate were reacted with a 8.7-fold molar excess of $\mathrm{NaOCl}$. After $80 \mathrm{~s}$, the reactions were quenched with a 2.5 -fold molar excess of $\mathrm{NH}_{4} \mathrm{Cl}$ relative to the initial $\mathrm{NaOCl}$ concentration and analyzed repeatedly by HPLC. Figure S1 shows plots of the cimetidine chlorination product concentrations normalized to their concentrations at the first HPLC injection ( 3 min after quenching) vs. time after quenching. Due to the short reaction time, it was difficult to obtain a true "time $=0$ " point by injecting unquenched samples on the HPLC at $80 \mathrm{~s}$ to determine the initial product concentrations to normalize the subsequent time points to. Figure $\mathrm{S} 1$ indicates that the cimetidine chlorination products are very stable at each $\mathrm{pH}\left(<6 \%\right.$ change from initial concentration) in the presence of $\mathrm{NH}_{4} \mathrm{Cl}$-quenched free chlorine, except the sultam $(<18 \%$ change from initial concentration).

Overall, these control experiments show that $\mathrm{NH}_{4} \mathrm{Cl}$ effectively quenches the free chlorine reactions described in this work. 
(A) $\mathrm{pH} 4$
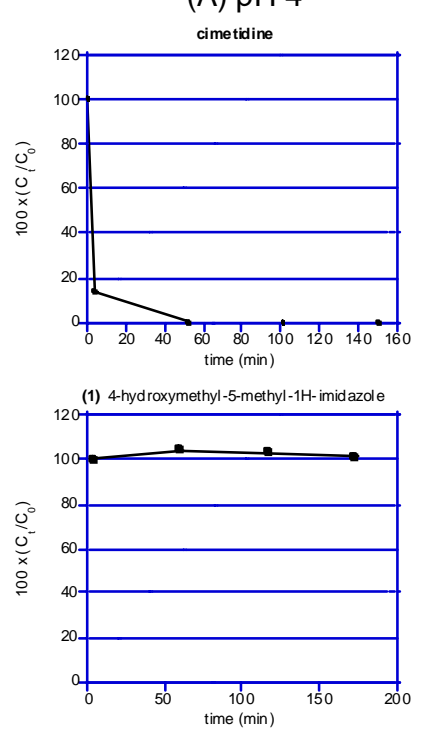

(2) cimetidine sulfoxide
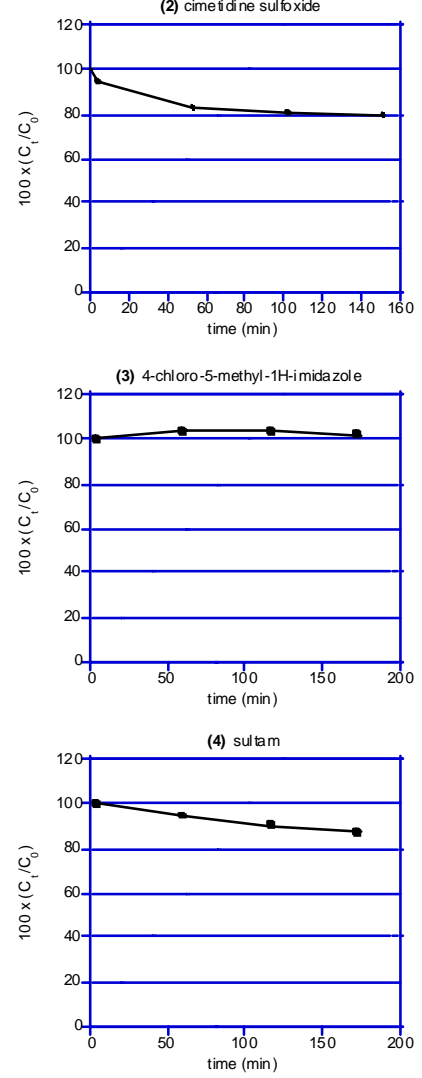

(B) $\mathrm{pH} 7$
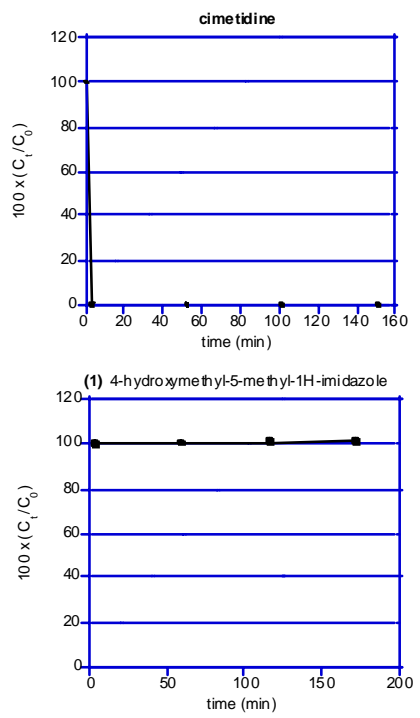

(2) cimetidine sul foxide
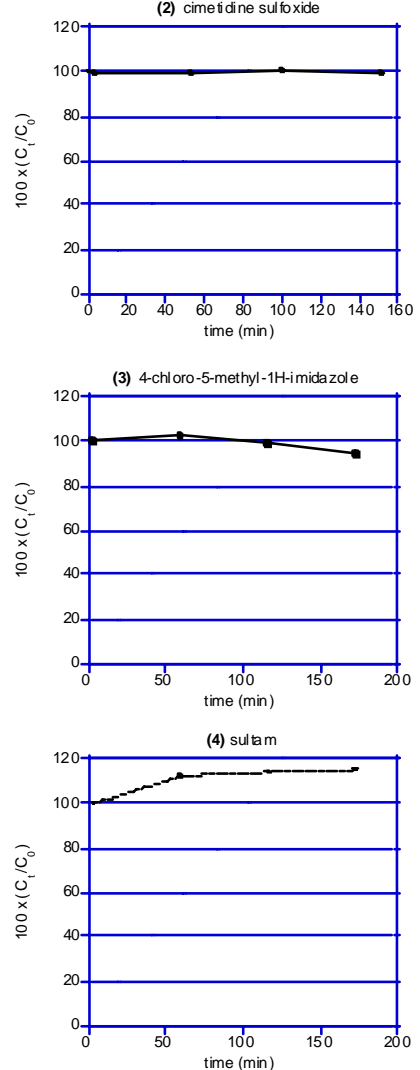

(C) $\mathrm{pH} 10$
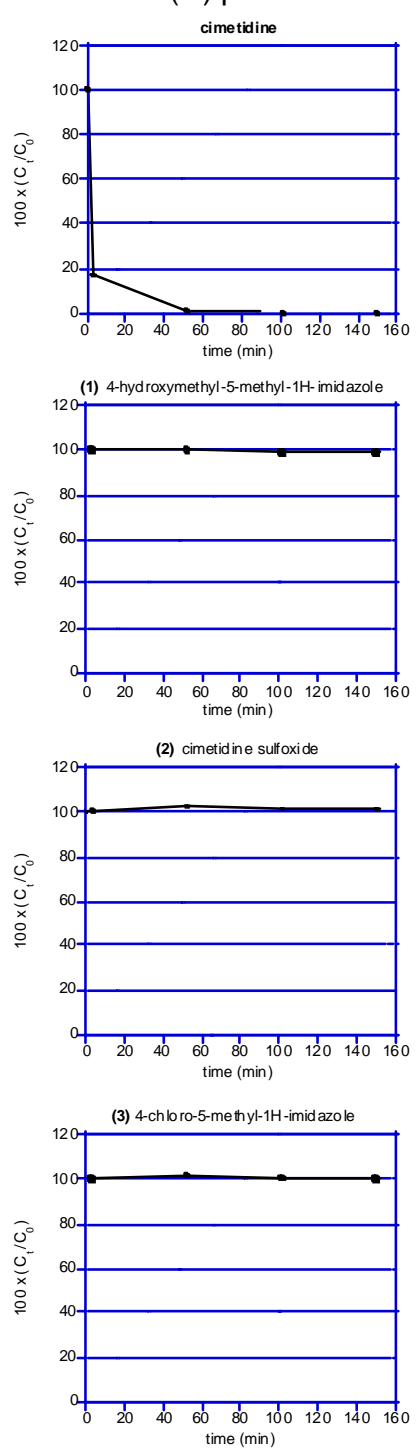

(4) sultam

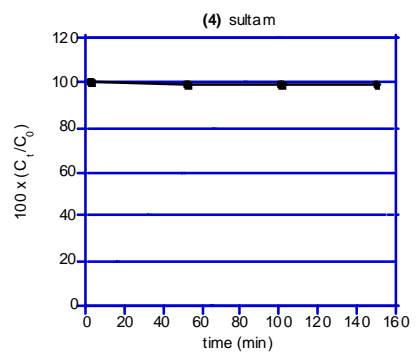

Figure S1. Stability of cimetidine and its chlorination products in the presence of chloramines formed in the free chlorine quenching reaction with $\mathrm{NH}_{4} \mathrm{Cl}$ at $\mathrm{pH} 4$ (Panel $\mathrm{A}$ ), 7 (Panel B), and 10 (Panel C). For cimetidine and cimetidine sulfoxide plots, quenching preceded substrate addition, and the $\mathrm{x}$-axis represents time after substrate addition while the $y$-axis represents the concentration of cimetidine normalized to its initial concentration. For the other product plots, free chlorine was quenched after $80 \mathrm{~s}$ of cimetidine chlorination, and the $\mathrm{x}$-axis represents the time after quench while the $\mathrm{y}$-axis represents the product concentrations normalized to their concentrations at the first HPLC injection. 

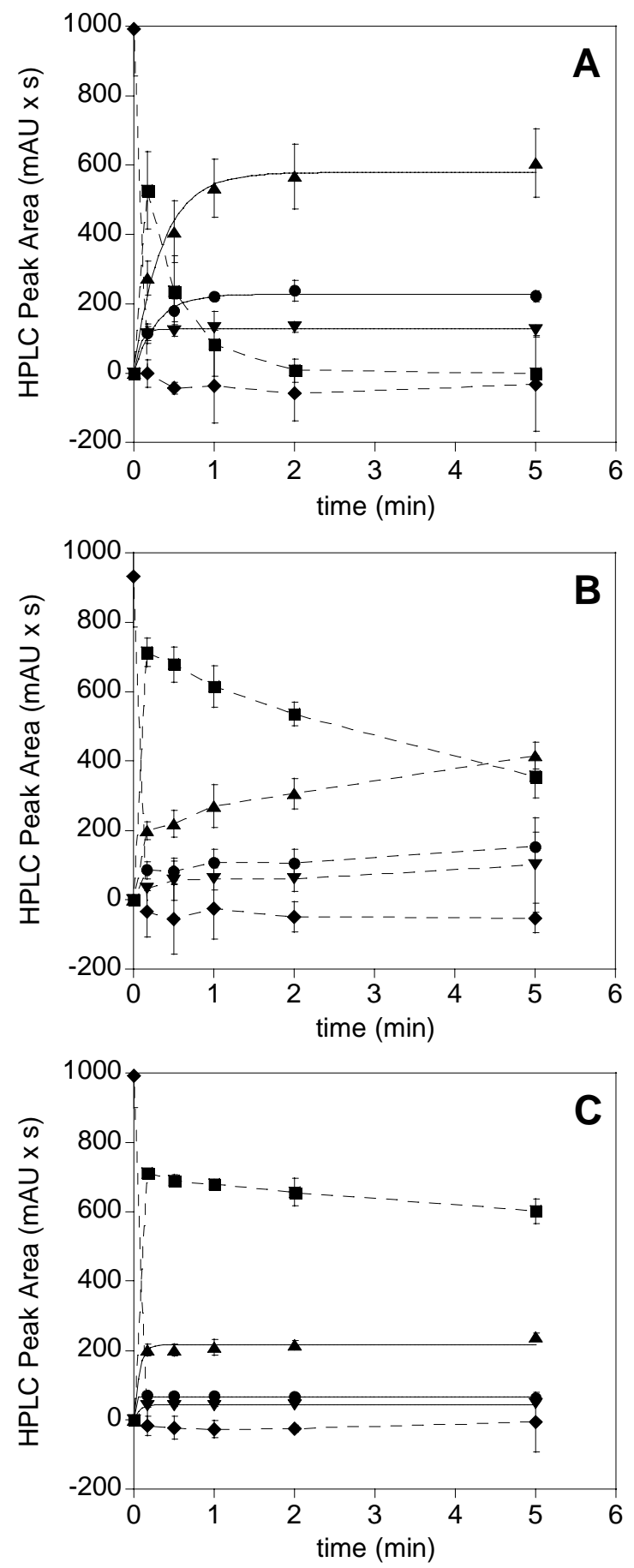

Figure S2. Degradation of $100 \mu \mathrm{M}$ cimetidine ( $\bullet$ ) and evolution of its chlorination products $\mathbf{1}(\bullet), \mathbf{2}(\mathbf{\bullet}), \mathbf{3}(\mathbf{\Delta})$, and $\mathbf{4}(\boldsymbol{\nabla})$ upon the addition of a 10-fold molar excess of free chlorine in wastewater at pH 4 (A), 7 (B), and 10 (C). Cimetidine peak areas are corrected by subtracting out the peak area of a co-eluting interferent in the wastewater. Solid lines represent fits to exponential growth equations $\left(\mathrm{R}^{2} \geq 0.99\right)$. Dashed lines do not represent mathematical fits; they were added for the purpose of visualization. Error bars denote the $95 \%$ confidence interval for $n=3$. 


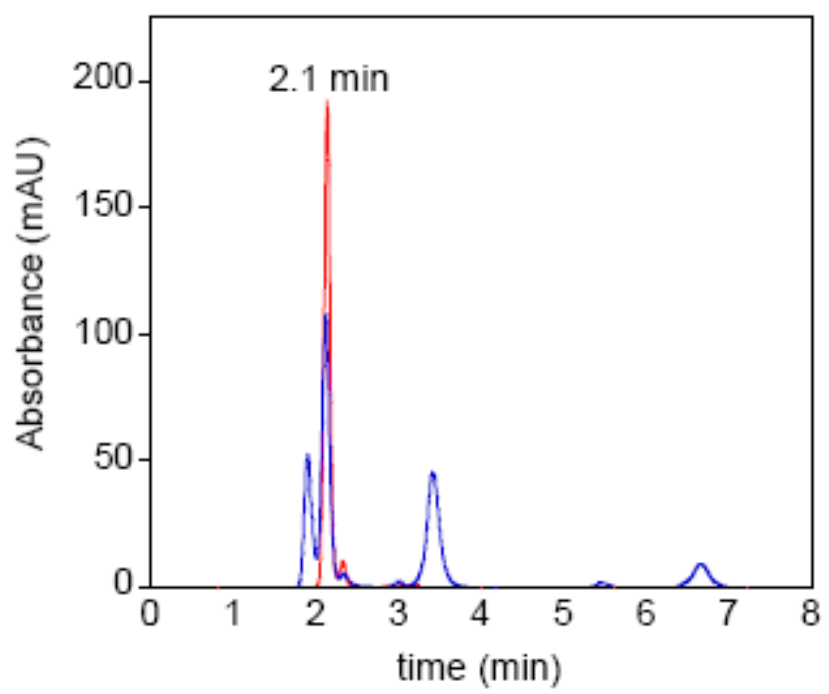

Figure S3. HPLC chromatograms comparing the retention times of authentic cimetidine sulfoxide (-) to those of the products formed by reacting $200 \mu \mathrm{M}$ cimetidine with a 3 -fold molar excess of free chlorine for $3 \mathrm{hr}$ in DI water at $\mathrm{pH} 7$ (-). The retention time match at 2.1 min provides evidence for cimetidine sulfoxide as the identity of product 2 .

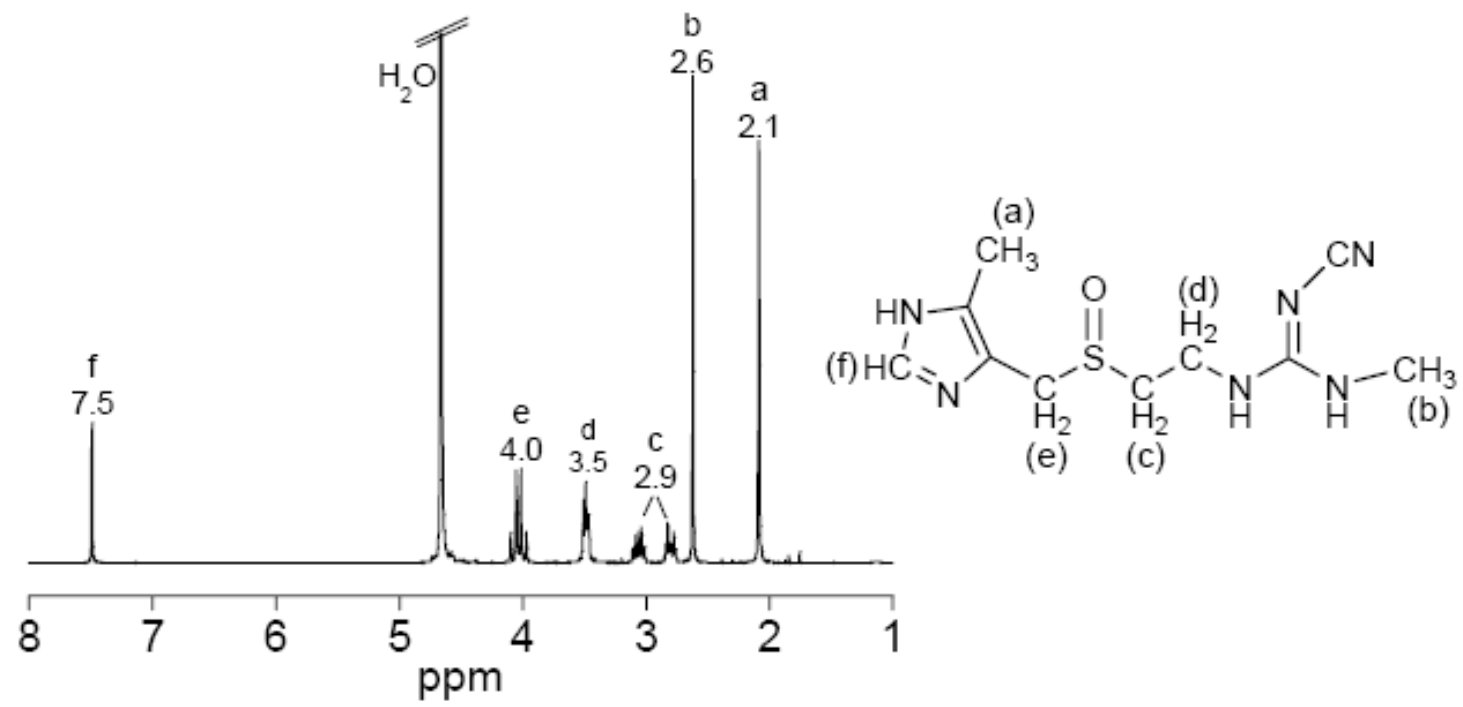

Figure S4. ${ }^{1} \mathrm{H}-\mathrm{NMR}$ spectrum of product 2 (cimetidine sulfoxide) isolate in $\mathrm{D}_{2} \mathrm{O}$ and its structure labeled with the corresponding $\mathrm{H}-\mathrm{NMR}$ peak assignments. 


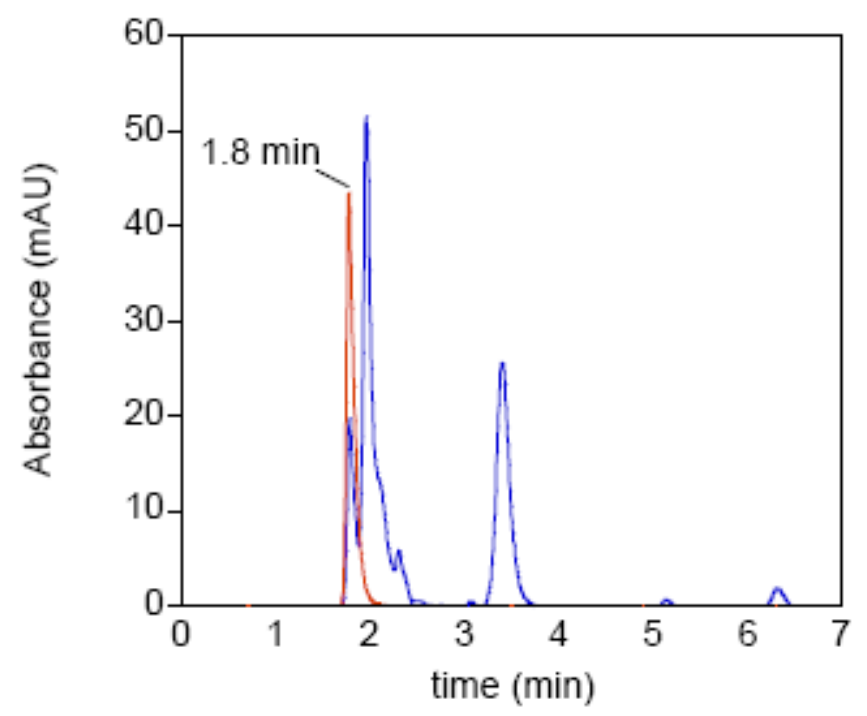

Figure S5. HPLC chromatograms comparing the retention times of authentic 4hydroxymethyl-5-methyl-1H-imidazole $(-)$ to those of the products formed by reacting $100 \mu \mathrm{M}$ cimetidine with a 10-fold molar excess of free chlorine for $30 \mathrm{~s}$ in DI water at $\mathrm{pH} 7$ (-). The retention time match at 1.8 min provides evidence for 4-hydroxymethyl-5-methyl$1 \mathrm{H}$-imidazole as the identity of product 1.

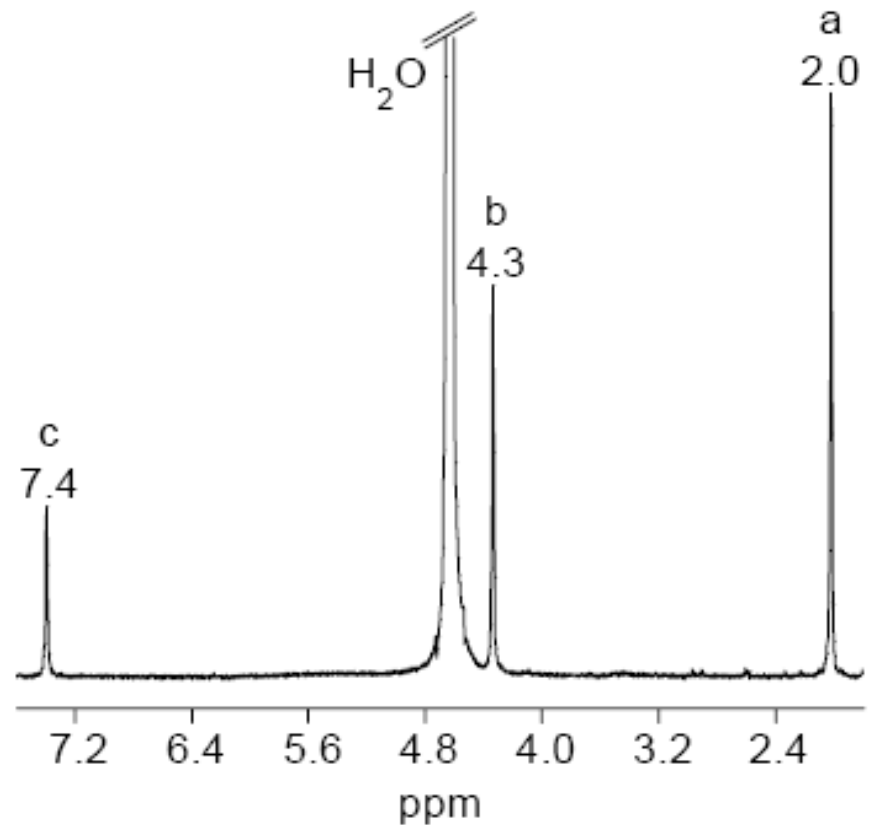<smiles>Cc1[nH]cnc1CO</smiles>

Figure S6. 'H-NMR spectrum of product 1 (4-hydroxymethyl-5-methyl-1H-imidazole) isolate in $\mathrm{D}_{2} \mathrm{O}$ and its structure labeled with the corresponding $\mathrm{H}-\mathrm{NMR}$ peak assignments. 

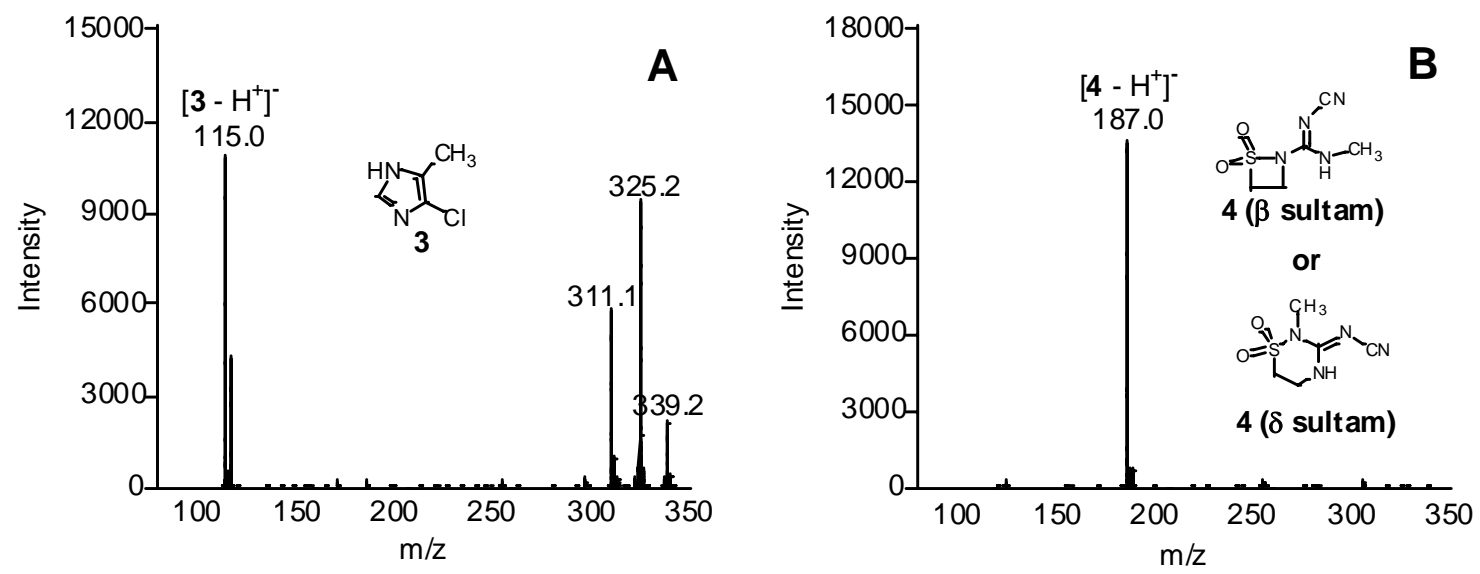

Figure S7. ESI ${ }^{-}$mass spectra of (A) Product 3 (4-chloro-5-methyl-1H-imidazole) and (B) Product 4 ( $\beta$-sultam: N-cyano-N'-methyl-N"'- $\beta$-sultamylguanidine or $\delta$-sultam: N-(2-methyl1,1-dioxide-1,2,4-thiadiazinan-3-ylidene)cyanamide) isolated from a cimetidine chorination reaction mixture. 

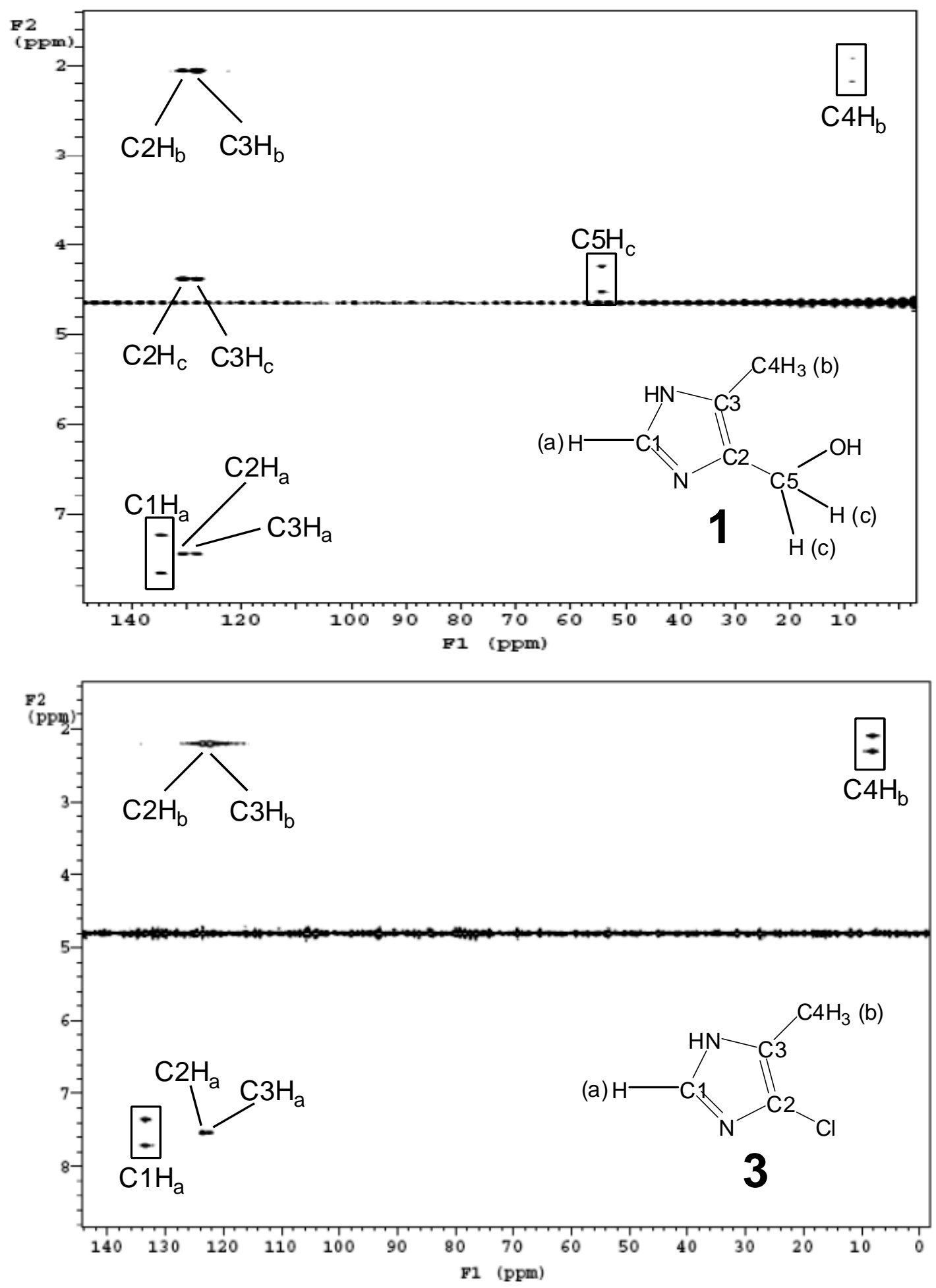

Figure S8. ${ }^{1} \mathrm{H} /{ }^{13} \mathrm{C}$ heteronuclear multiple bond correlation (HMBC) nuclear magnetic resonance spectra of isolates of $\mathbf{1}$ (top) and $\mathbf{3}$ (bottom) dissolved in $\mathrm{D}_{2} \mathrm{O}$ with labeled structures. The ${ }^{13} \mathrm{C}$ chemical shift is displayed on the $\mathrm{F} 1$ axis while the ${ }^{1} \mathrm{H}$ chemical shift is displayed on the F2 axis. 

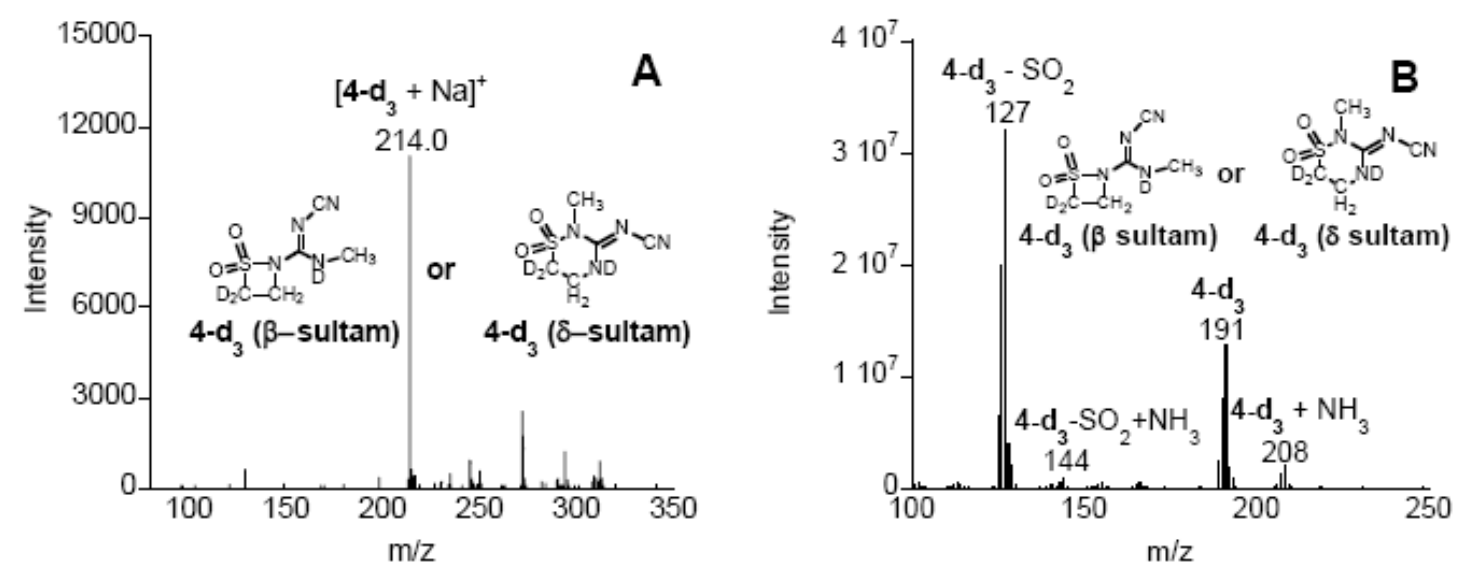

Figure S9. (A) ESI ${ }^{+}$mass spectrum of deuterated product $4\left(4-d_{3}\right)$ showing a peak at $3 \mathrm{~m} / \mathrm{z}$ units higher than the un-deuterated product, indicating that $\mathbf{4}$ has three exchangeable protons. (B) CI mass spectrum of 4-d $\mathbf{d}_{3}$, revealing the parent ion peak as well as a fragment $64 \mathrm{~m} / \mathrm{z}$ units lower than the parent, likely attributable to the loss of $\mathrm{SO}_{2}$ from the compound. Ammonia adducts of these two ions were detected as well.
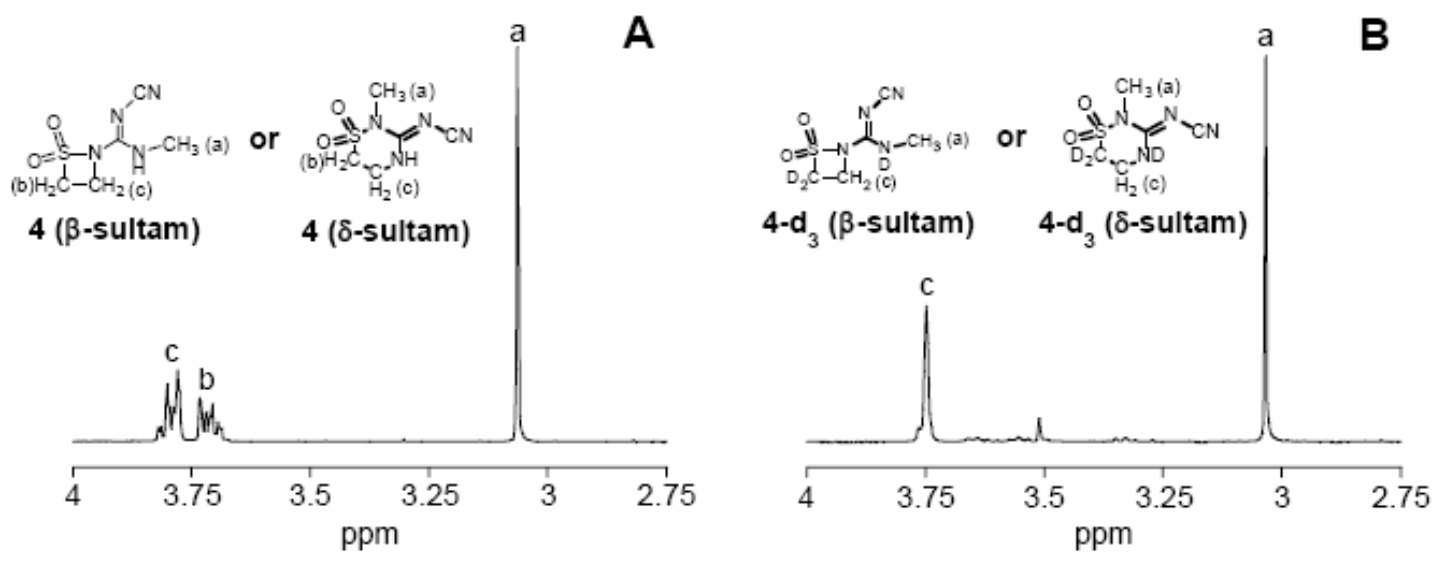

Figure S10. ${ }^{1}$ H-NMR spectra of (A) product 4 prior to deuterium exchange and (B) deuterated product $\mathbf{4}\left(\mathbf{4 - d _ { 3 }}\right)$ with ${ }^{1}$ H-NMR peak assignments labeled on the structures. 

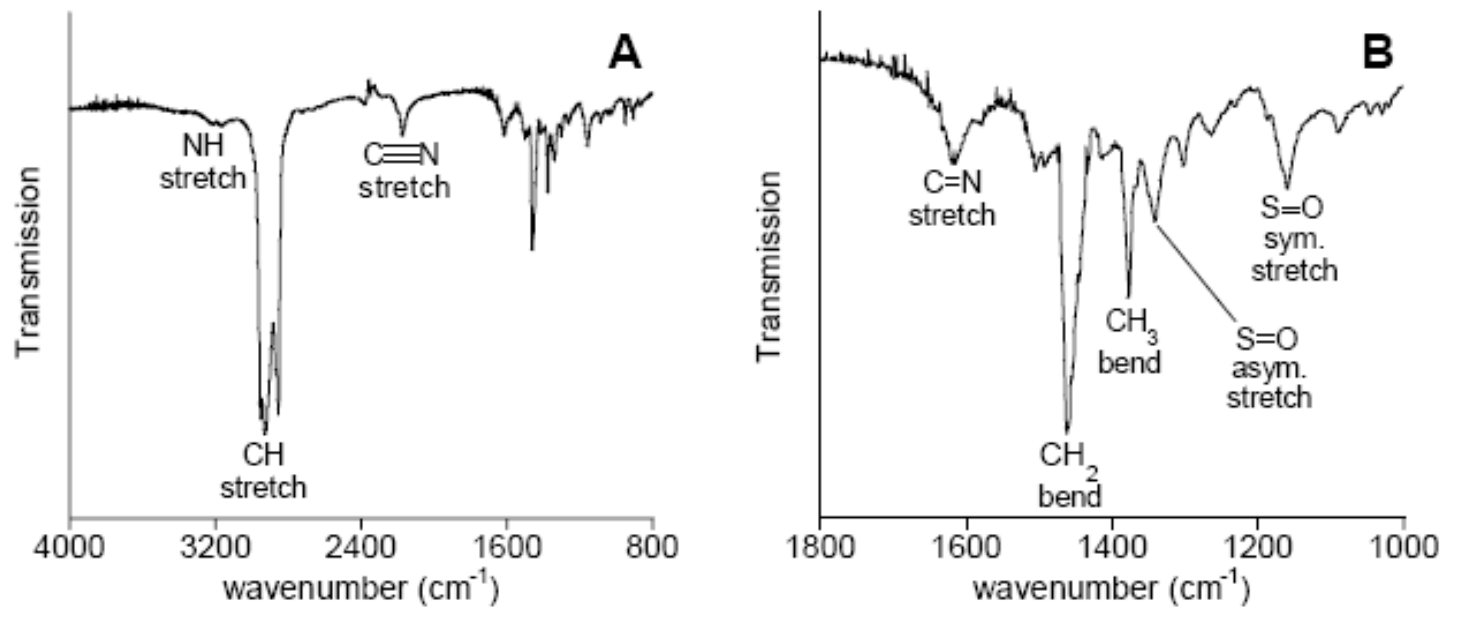

Figure S11. Infrared spectra of isolated product 4: (A) full wavelength range and (B) zoomin of low wavelength region.

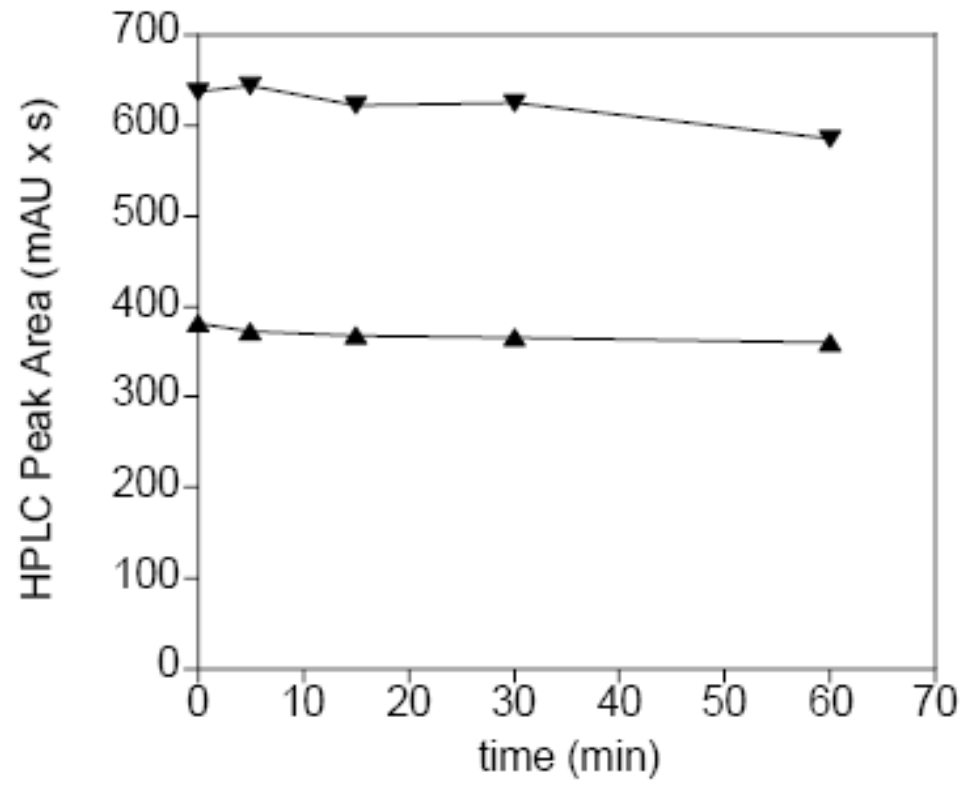

Figure S12. Degradation of $3(\Delta)$ and $4(\nabla)$ in the presence of a $\sim 10$-fold molar excess of free chlorine in $\mathrm{pH} 7 \mathrm{DI}$ water, showing both products to be relatively unreactive. 


\section{Works Cited}

(1) Aiken, G.; Kaplan, L. A.; Weishaar, J. Assessment of relative accuracy in the determination of organic matter concentrations in aquatic systems. J. Environ. Monit. 2002, 4, 70-74.

(2) Gerhardt, P. M., R. G. E.; Wood, W. A.; Krieg, R. R., Ed. Methods for General and Molecular Bacteriology.; American Society of Microbiology: Washington, D.C., 1994, pp 541-542.

(3) Dodd, M. C.; Huang, C.-H. Transformation of the antibacterial agent sulfamethoxazole in reactions with chlorine: Kinetics, mechanisms, and pathways. Environ. Sci. Technol. 2004, 38, 5607-5615. 